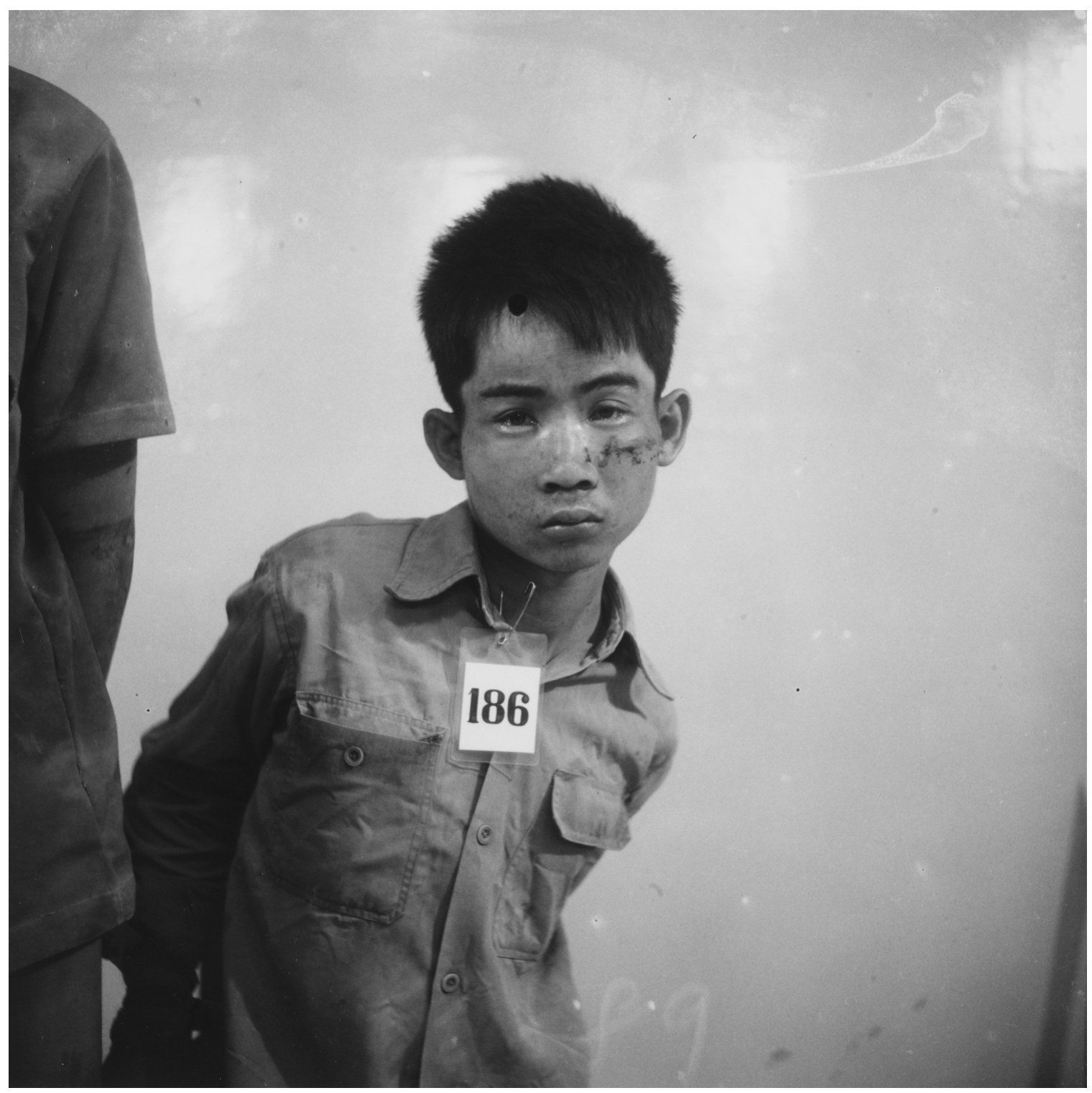




\section{A arte diante do mal radica*}

\section{Thierry De Duve}

palavras-chave:

arte contemporânea; fotografia; instituições de arte; Nhem Ein, ,julgamento estético

keywords: contemporary art; photography; art institutions,;

Nhem Ein; aesthetic judgement

O objeto principal de discussão deste ensaio é a aquisição, para o acervo do Museu de Arte Moderna de Nova Iorque, de um conjunto de fotos de identidade de civis mantidos em campos de extermínio pelo regime de Pol Pot (líder do Khmer Vermelho cambojano entre 1975 e 1979 e responsável pelo massacre sistemático de milhares de civis durante esse período), feitas por um jovem a serviço do governo, especialmente treinado na prática fotográfica para tal fim. Tratava-se, conforme relato do jovem, de um ritual burocrático que antecedia a execução sumária dos prisioneiros. $\mathrm{O}$ autor argumenta que a exibição pública das fotos em evento cultural e logo sua incorporação ao acervo de um grande museu de arte, em 1997, implicaram a institucionalização e a naturalização dessas imagens como objetos de arte, e denuncia o fracasso, à luz desses dois episódios, dos princípios que serviram tradicionalmente à legitimação humanista da arte e das instituições de arte.

The main subject of this essay is The Museum of Modern Art of New York's purchasing an ensemble of identity photographs took by a young servant of Pol Pot's regime (the leader of Cambodian Khmer Rouge between 1975 and 1979, who exterminated thousands of civilians during this period), specially enrolled in a professional training of photography for this purpose. As reported by the youth, he just felt himself as someone engaged in a bureaucratic ritual, previous to the execution of the prisoners. The author argues that the public exhibition of the photos in a cultural event, and then they being incorporated, in 1997, to the permanent collection of an important art museum have carried the institutionalization and the naturalizing of these images into art objects; he also denounces, in the light of these episodes, the failure of the premises which traditionally grounded the humanist legitimization of art and art institution.

\footnotetext{
Prisioneiro do Campo S-21, no Camboja, c. 1978. Foto: cortesia do Photo Archive Group, Califórnia, EUA.
} 
* Este texto foi apresentado ao público brasileiro numa das conferências do II Simpósio Pensar a Arte Hoje/ perspectivas críticas, organizado pelo Centro de Pesquisas em Arte Brasileira do Departamento de Artes Plásticas da ECA-USP e pelo Centro Universitário Mariantonia, em 2005. Uma versão do texto foi também apresentada no Congresso

Internacional de Estética, em Ancara, 2007.

1 Apud SONTAG, Susan. On photography. Nova lorque: Farrar, Strauss e Giroux, 1977, p. 199.

2. RILEY, Chris; NIVEN, Douglas (Ed.). The killing fields. Santa Fé: Twin Palm Publishers, 1996.
Um objeto que fala de perda, destruição, desaparecimento de objetos. Não fala de si mesmo. Fala de outros. Será que os inclui?

Jasper Johns ${ }^{1}$

Primeiro, as fotos, sem interpretação ou comentários.

Segundo, os fatos. Todo verão, a cidade de Arles, no sul da França, organiza um festival importante de fotografia chamado "Les rencontres photographiques d'Arles" [Encontros fotográficos de Arles], com dezenas de exposições espalhadas pela cidade. Em 1997, o evento teve direção artística de Christian Caujolle, cofundador e diretor artístico da agência francesa de fotografia $V u$ e antigo editor-chefe de imagens do Libération. Caujolle foi o curador, entre várias outras exposições, de "S-21", composta de cem retratos ou fotografias de identidade (não sei exatamente como chamá-los) de vítimas do genocídio no Camboja. "S-21" é o nome de um antigo colégio do bairro de Tuol Sleng, em Phnom Penh, que Pol Pot transformou em centro de tortura e campo de extermínio. Entre 1975 e 1979, 14.200 pessoas foram brutalmente executadas no S-21, no próprio local ou em campos próximos. Existem sete sobreviventes. Em razão do regulamento e da burocracia do regime, todo homem, mulher e criança que entrava no centro era fotografado antes de ser morto. Para desempenhar essa função hedionda, um membro do Khmer Vermelho de 15 anos de idade, chamado Nhem Ein, foi enviado a Xangai para estudar fotografia e, um ano depois, era promovido a "fotógrafo-chefe" no S-21, com cinco funcionários sob seu comando. Quando os vietnamitas libertaram o centro em 1979, cerca de 6.000 negativos foram achados. Em 1994, dois fotojornalistas americanos, Chris Riley e Douglas Niven, incumbiram-se de restaurar e revelar os negativos em nome da Photo Archive Group, uma organização sem fins lucrativos fundada por eles. Cem fotos foram ampliadas e mostradas ao redor do mundo, para que o genocídio cambojano - ou autogenocídio, como alguns preferem dizer - não fosse esquecido. Um livro com as fotos foi publicado dois anos mais tarde, com o título The killing fields ${ }^{2}$ [Os campos de extermínio]. Em 2002, Rithy Panh, que teve a família exterminada pelo Khmer Vermelho, fez um filme com o objetivo de investigar o passado traumático do Camboja; no filme, dois sobreviventes são confrontados com alguns de seus carcereiros, para elaborar o trauma. O filme se chama "S-21: The Khmer Rouge killing machine” [S-21: A máquina de extermínio do Khmer Vermelho].

A escola é hoje o Museu Tuol Sleng do Genocídio. As fotos estão permanentemente expostas, a maioria em tamanho pequeno, e 
3. POMONTI, JeanClaude. Nhem Ein, photographe en chef des Khmers rouges. Le Monde, 5 jul. 1997. Ver, também, SMITH, Craig S. Profiting from his shots of Pol Pot's terror. Wall Street Journal, 16 set. 1997.

4. Declaração pública de Christian Cajoulle em Arles, 7 jul. 1997, apud DOCQUIERT, Françoise; PIRON, François (Ed.). Image et politique. Arles: Actes Sud, 1998, p. 104. com frequência são visitadas por familiares das vítimas, que vão render homenagem a seus próximos. O fotógrafo, Nhem Ein, está vivo e livre, e ainda se sustenta profissionalmente como fotógrafo em Phnom Penh. De acordo com uma entrevista que deu, ou melhor, vendeu ao Le Monde, na ocasião de "sua" exposição em Arles, fotografar era, para ele, simplesmente um trabalho como outro qualquer; nunca fora uma paixão. Trabalhar no S-2 1 não era uma escolha, disse. Era isso ou ser ele próprio morto. Ele tirou até 600 fotos por dia de pessoas que sabia serem inocentes e que haviam sido condenadas à morte; trabalhou como um autômato e fechou os olhos para o sofrimento dessas pessoas a ponto de fingir não reconhecer um primo que apareceu diante de sua câmera. Em 1979, acompanhou Pol Pot em seu refúgio nas florestas do norte e serviu como fotógrafo oficial do Khmer Vermelho até desertar em 1995, abandonando a mulher e seis filhos para servir ao regime pró-Vietnã de Hun Sen. Não sente nenhum remorso e, ao saber da exposição em Arles, afirmou estar orgulhoso de ser a "estrela" do festival de fotografia na França, com um grande sorriso estampado no rosto ${ }^{3}$.

Durante o festival "Rencontres photographiques d'Arles", que acontece em plena estação turística, a cidade inteira celebra a fotografia em todos os seus aspectos. Uma multidão de fotógrafos profissionais e amadores, críticos de fotografia e aficionados dos mais variados calibres circula pela cidade, câmeras e lentes penduradas no pescoço, vestidos um tanto comicamente com o colete de muitos bolsos à la Joseph Beuys, o qual se tornou o uniforme dos foto-jornalistas no mundo inteiro. Caujolle tinha, claro, consciência da função do festival para a indústria turística. Teve uma atitude crítica ao designar para o festival de 1997 a temática "ética, estética e política" e organizá-lo em três categorias: Formas de compromisso, O dever da memória e A tentação do poder. Desse modo, esperava criar um contexto no qual a exposição das ampliações feitas por Riley e Niven faria sentido. Inseriu a exposição "S-21" na rubrica O dever da memória. Em entrevistas, afirmou muito claramente que suas razões para incluir "S-21" no festival eram políticas e não estéticas - em suas próprias palavras, "para nos lembrar que dois milhões de pessoas, de uma população de sete milhões, foram massacradas [no Camboja], e que ninguém se moveu" ${ }^{\text {. }}$ Mesmo assim "S-21" era uma entre dezenas de exposições, algumas das quais tinham motivações nitidamente estéticas, e não estava sozinha em $\mathrm{O}$ dever da memória. $\mathrm{O}$ press-release divulgado pelo festival anunciava que Esther Shalev-Gerz e Jochen Gerz, artistas bastante conhecidos, exporiam na mesma categoria, apesar de posteriormente a exposição deles ser transferida para Formas de compromisso, e assim 
5. GUERRIN, Michel. La photographie documentaire surexposée. Le Monde, 6 jul. 1997. minado meio, que a fotografia ultimamente passou a exemplificar. Pensemos, por exemplo, na diferença, feita no mundo da arte diariamente e sem maiores problemas, entre fotógrafos e "artistas-que-usamfotografia". Ambos os grupos são vistos como artistas - os primeiros, definidos como praticantes de uma dada arte, do mesmo modo que os pintores ou os escultores; os últimos, como artistas em sentido amplo, que por acaso se expressam através da fotografia como meio. Verdadeiras guerras ideológicas e estéticas são por vezes travadas em nome de uma ou outra dessas definições de artista. É bastante irônico que muitos foto-jornalistas defendam a especificidade de seu meio, prosaico e de natureza documentária, para explicar a razão pela qual não se importam em ser considerados artistas, ao passo que a especificidade do meio é igualmente o divisor de águas no raciocínio modernista, a partir do qual críticos como John Szarkowski, o antigo curador de fotografia do Museu de Arte Moderna de Nova Iorque, promoveram a fotografia dentro do museu e lhe concederam as credenciais de arte. Que espécie de distinção obscura faz o press-release do festival de Arles entre repórteres fotográficos, quando despacha Marthieu Pernot para a categoria de "jovem artista", ao mesmo tempo em que apresenta Klavdij Sluban como alguém que "transforma imagens documentárias em fotografia”[sic]? Devemos presumir que Pernot é um artista-que-usafotografia, em consonância com a definição institucional de arte que prevalece atualmente no mundo da arte, ao passo que as fotos jornalísticas de Sluban são elevadas a exemplos de "fotografia" (fotografia em si, fotografia como tal), em consonância com a definição da estética modernista da arte, que prevalece em instituições como o MoMA? E por falar em MoMA: enquanto as fotos do Camboja estavam em cartaz em Arles, Le Monde publicou um artigo escrito pelo crítico de fotografia do jornal, Michel Guerrin, afirmando que elas tinham "adquirido status ‘artístico' por entrarem para coleções de museus prestigiados, como os Museus de Arte Moderna de Nova Iorque, São Francisco e Los Angeles" ${ }^{5}$. Apesar do artigo de Guerrin não mencionar o fato, chegava a Arles a notícia de que o MoMA estava expondo as fotos. Essa notícia, combinada à publicidade do festival e ao status flutuante de várias de suas exposições, levou muitos a especularem sobre a razão da aquisição do MoMA e contaminou a exposição "S-21" em Arles pelo suposto status de arte das fotos, inevitável por estarem no MoMA. Não pressupor que as fotografias, ou pelo menos aquelas que o MoMA comprara, podiam ou mesmo deviam ser vistas como arte ficou bastante difícil. Se Nhem Ein e seus assistentes deveriam ou não, por implicação, ser considerados artistas - e se essa categorização seria estética, ética ou politi- 
camente defensável (para citar a fórmula de Caujolle) - era uma ideia que deixou todo mundo desconfortável em Arles, naquele verão, embora tivesse ocorrido a todos. Caujolle não era, claro, responsável pela aquisição do MoMA e não poderia ser censurado pelo fato de que o status já problemático das fotos no festival era exacerbado pelo conhecimento público de que elas estariam em cartaz em um museu importante. Mas, em 1997, em Arles, a decisão do MoMA de colecionar e expor as fotos de Nhem Ein foi motivo de confusão. Com a distância que temos hoje, essa mesma decisão pode ser colocada em pauta para se desfazer a confusão e para que ajudemos a esclarecer a questão que é o tema central do meu texto: examinar a legitimidade da arte e da instituição de arte em face do mal radical. Essas fotos fornecem um exemplo particularmente perturbador, que de modo insuportável se torna ambíguo, pelas oscilações de status da fotografia dentro de um festival cuja razão de ser girava em torno da divisa "ética, estética e política”. Em contraposição, a razão do MoMA existir não é de forma alguma ambígua. É para colecionar e expor arte, não para promover o dever da memória ou testemunhar as monstruosidades geradas pela insanidade política.

Colecionar e expor arte são, por definição, as principais funções de um museu de arte. A legitimação humanista usual de um museu de arte proclama que a arte é um bem coletivo da humanidade; a esfera pública do museu está, dessa maneira, fundada em seu caráter de patrimônio. $\mathrm{O}$ argumento humanista sustenta que se a humanidade possui esse bem coletivo chamado arte, o público tem direito de acesso a ele. Do mesmo modo, a legitimação humanista da prática da arte está ligada à noção de que artistas são porta-vozes da humanidade no domínio estético, e portanto postula a legitimidade do artista para falar em nome de todos nós. Há uma dialética circular na argumentação humanista: a legitimidade do museu em última análise depende dos artistas, ao mesmo tempo em que a legitimidade dos artistas depende de sua contribuição para o museu. E ambas baseiam-se na premissa circular de que o respeito pelo humano define o humano. Supõe-se que todo trabalho de arte, tendo alcançado seu lugar no patrimônio coletivo, contenha algo que seja de interesse dos seres humanos em geral, algo que expresse, alimente e recompense a humanidade com humanidade - quero dizer, a condição humana da espécie humana. Se Nhem Ein fosse chamado de artista, ele teria que ser considerado um representante legítimo da espécie humana como um todo, e tal ideia é obscena. Além disso, a expressão da condição humana emanando das fotografias de Nhem Ein, tão inacreditavelmente comoventes, tocantes, 
6. CRIMP, Douglas. On the museum's ruins. In: On the museum's ruins. Cambridge, Mass.: MIT Press, 1993. p. 44-64. Cf. edição brasileira: Sobre as ruínas do museu. In:

Sobre as ruínas do museu. São Paulo: Martins Fontes, 2006. inquietantes e carregadas de tragédia humana como são, teria de ser atribuída à sensibilidade dele para com o humano na espécie humana, em outras palavras, à sua empatia com aqueles que fotografa, o que é ainda mais obsceno. Se a raison d'être do MoMa - colecionar e expor arte - deve ser justificada nos termos humanistas que acabo de delinear, ao decidir colecionar e expor as fotos de Nhem Ein, o MoMA, portanto, teria nada menos do que deslegitimado sua própria existência.

Não estou feliz com isso. Aprecio museus tanto quanto aprecio arte, e não me alegro com a perspectiva de dançar "sobre as ruínas dos museus", para citar a conhecida crítica que Douglas Crimp fez da instituição de arte, crítica que se baseia - não por acaso, e eu penso que com razão - na convicção de que o cavalo de Troia que penetrou o museu é a fotografia ${ }^{6}$. Compartilho com Crimp sua profunda desconfiança sobre a legitimação humanista da arte e dos museus de arte. No entanto, diferentemente dele, não acredito nem um pouco que museus de arte perderam ou devam perder sua legitimidade. Sofrem - e isto é bastante diferente - o risco de se tornarem parques de diversão geridos pelo setor privado para fins lucrativos, com a ajuda involuntária de acadêmicos de esquerda bem-intencionados que veem como vitória dissolver a singularidade da "arte" na relatividade heterogênea das "práticas culturais". Penso que museus de arte precisam com urgência de uma legitimação diferente da humanista, para a qual as fotografias do S-21 podem representar o mais justo - por ser quase inconcebível teste de realidade. Descrevo, resumidamente, como eu esboçaria essa legitimação alternativa. Museus de arte são instituições, eu argumentaria, onde artefatos humanos são colecionados e preservados sob o nome de arte e apresentados em nome da arte. O status de qualquer objeto pertencente à coleção de um museu de arte depende de dois procedimentos distintos: o julgamento estético que comparou o objeto com a arte já existente e confirmou que ele merece ser preservado como arte, e a exposição pública do objeto em nome, precisamente, de sua comparabilidade com a coleção de objetos que atua como critério de comparação. Dessa maneira, como regra, museus de arte colecionam e preservam coisas como sendo arte e as exibem em nome da arte. Aí reside sua legitimidade. Museus com outras designações não realizam nenhum dos dois procedimentos: por mais belos que sejam os dioramas do Museu de História Natural de Nova Iorque, os animais empalhados exibidos não são preservados como trabalhos de arte, tampouco mostrados em nome de uma coleção esteticamente constituída de trabalhos de arte. Com o intuito de esclarecer a noção confusa de "status de arte", talvez seja útil primeiro fazer a distinção clara entre as duas funções dos 
7. Cf. o texto do pressrelease da exposição "Photographs from S-21: 1975-1979". Nova lorque: Museum of Modern Art, 15 maio/ 30 set. 1997.

8. Para um enfoque da história do departamento de fotografia do MoMA oriundo do próprio departamento, ver GALASSI, Peter.

Two stories. In: American photography 1890-1965. Nova Iorque: Museum of Modern Art, 1995. Para um enfoque crítico externo, ver PHILLIPS, Christopher. The judgment seat of photography. October, n. 22, outono 1982. p. 27-65. museus de arte e os procedimentos a elas correspondentes, como brevemente os descrevi, já que assim nos deparamos com duas anomalias interessantes: o caso em que coisas sem dúvida colecionadas como trabalhos de arte não são exibidas em nome da arte - por exemplo, a "Lição de anatomia" de Rembrandt em uma exposição documentária sobre a história da cirurgia - e o caso em que coisas não necessariamente reconhecidas como trabalhos de arte são, todavia, exibidas em nome da arte - "S-2 1" sendo um exemplo extremo, se não em Arles, por certo em Nova Iorque.

Não vi a exposição do MoMA. Ela recebeu o solene título de "Fotografias de S-21: 1975-1979" e trazia as oito fotos compradas pelo museu, junto com outras 14, em ampliações de tamanho modesto, emolduradas e acondicionadas em passe-partouts. Foi instalada na Galeria Três, que fica no final da antiga ala de fotografia do MoMA e é anunciada como

um lugar onde os visitantes podem fazer uma pausa para sentar e refletir, e onde curadores do museu podem compartilhar seu entusiasmo por certas fotos, suas reflexões sobre certos episódios na fotografia e suas investigações sobre a rica coleção do museu. ${ }^{7}$

O departamento de fotografia do MoMA vem há tempos admitindo em sua coleção fotos que obviamente não foram realizadas como trabalhos de arte e cuja condição vernacular, conforme os curadores têm inúmeras vezes insistido, deve ser levada em conta quando são expostas ${ }^{8}$. Presumidamente, o estatuto especial da Galeria Três serve para facilitar essa atitude. Não há, entretanto, garantia de que ele funcione, porque o MoMA sendo um museu de arte, qualquer coisa que apresente é, inevitavelmente, exibida em nome de sua comparabilidade com a arte já existente e está, desse modo, reivindicando para si o rótulo de "arte". Daí a confusão que os visitantes devem sentir ao percorrer algumas galerias - as de design industrial e de fotografia sendo exemplos eloquentes: eles são convidados a contemplar objetos que não são de arte tendo a arte como referência. Daí, igualmente, o desconforto dos curadores com o dilema arte/ não arte, e os tantos contestadores que sempre acompanharam exposições de fotografia vernacular do MoMA. Uma constante entre esses contestadores é negarem que os fotógrafos tenham tido intenção artística quando tiraram as fotos, ao mesmo tempo em que reconhecem nos curadores preocupação estética quando as mostram. O resultado é um astuto descarte da embaraçosa palavra arte em favor de sua hipóstase na especificidade do meio, "fotografia". Um exemplo seria a caracterização feita por Edward 
9. Apud GALASSI, op. cit., p. 11.

10. SZARKOWSKI, John. The photographer's eye. Nova lorque: Museum of Modern Art, 1966. Não paginado.

11. Peter Galassi, em e-mail ao autor, 4 jul. 2005. Sou profundamente grato a ele por ter permitido que eu compartilhasse de grande parte da documentação acumulada pelo departamento durante a preparação de "Fotografias do S21 ", e por ter meticulosamente respondido às tantas perguntas que the fiz.

12. John Szarkowski, nos textos do pressrelease e de parede para a exposição “Once invisible". Nova lorque: Museum of Modern Art, 20 jun. / 11 set. 1967.
Steinchen das fotos anônimas exibidas em sua exposição "Fotógrafos esquecidos", de 1951, como "exemplos de fotografia de qualidade notável" - de fotografia, ponto final'. Outro seria a afirmação de Szarkowski, em The photographer's eye [O olho do fotógrafo], de que o senso de realidade e a técnica do artista-fotógrafo são "dons anônimos e impenetráveis da fotografia em si” ${ }^{\prime 10}$. E ainda um outro é dado pelo atual curador-chefe de fotografia do MoMA, Peter Galassi, ao afirmar que "qualquer espécie de fotografia, não importa o propósito para o qual tenha sido feita, é potencialmente relevante para o estudo da fotografia em geral" ${ }^{11}$. "A fotografia" (a fotografia, ponto final), "a fotografia em si" e "a fotografia em geral" são expressões a sugerirem não apenas que algumas fotos são dignas de apreciação estética, mas também que a fotografia em geral - "o todo indiferenciado dela”, nas palavras de Szarkowski -, o próprio meio, resiste à comparação com outros meios artisticamente reconhecidos naquilo que concerne a um potencial estético. Não há dúvida de que ela resiste; não vejo nenhum problema em admitir que nem todos os fotógrafos (ou, a esse respeito, nem todos os pintores) precisam ser chamados de artistas para que o meio no qual se lançam seja reconhecido como uma forma de arte. $\mathrm{O}$ que defendo é que, se uma foto em particular convoca a possibilidade de se compará-la a trabalhos e formas de arte existentes, ela não pode esquivar o fato de que reivindica ou afirma o rótulo "arte" para si própria, não importando o quão simplória, inartística e vernacular seja ou pareça ser. Isso é verdade no MoMA, em Arles, ou em qualquer lugar; o contexto do museu simplesmente deixa explícito o problema da comparabilidade, pois seja o que for que o museu mostre, mostra-o em nome da arte, e o mesmo ocorre quando a palavra "arte" é evitada em nome de preocupações formais que são a marca registrada da grande arte. Tais preocupações foram claramente apontadas por Szarkowski em 1967, na apresentação de "Uma vez invisível", exposição de fotografias científicas (e portanto não artísticas) de coisas que existem fora dos limites do que se pode ver a olho nu, ao escrever que "trabalhos como estes são independentes das tradições artísticas e alheios a critérios estéticos”, apenas para um pouco adiante acrescentar que o tema da exposição era "a forma - a morfologia, não a função - das fotos exibidas"12.

Nem é preciso dizer, o texto de parede que apresenta "Fotografias de S-21" se abstém de formalismo tão explícito. Assinado pela curadora-assistente Adrienne Williams, que organizou a mostra, sobriamente afirma que, quando Chris Riley e Douglas Niven descobriram os negativos, "reconheceram que imagens tão poderosas como aquelas mereciam ser vistas por um público maior". Resta ao leitor inferir que 
13. I-JONG, Juan.

An interview with Chistopher Riley and

Douglas Niven.

Photographers International, n. 19, abril 1995, p. 96; 98.

14. Apud TREBAY, Guy. Killing fields of vision. The Village Voice, 3 jun. 1997.

15. Há, na formulação “Woody should speak of the emotional rapport the viewer has with subjects", um jogo de palavras com o termo subjects, que se poderia traduzir tanto como "temas" como “sujeitos" [N. T.].

16. BARTHES, Roland. Camera lucida.

Tradução Richard Howard. Nova lorque: Hill and Wang, 1981, p. 96 a curadora compartilha dessa opinião. Riley e Niven por sua vez são mais diretos: "Quando vimos os negativos originais seis por seis, percebemos que poderíamos ter ótimas ampliações”, disse Niven. Riley ratifica: "Poderíamos fazer ampliações de qualidade excepcional a partir desses negativos. E, com tal qualidade, conseguiríamos inseri-las em publicações, galerias e museus para alcançar um público mais amplo”. Indagado sobre se o projeto deles surgiu de um interesse fotográfico ou histórico, Riley respondeu, "nossa reação inicial foi puramente fotográfica”, e Niven acrescentou, "apesar de abordarem uma questão hedionda, sobre histórias hediondas, vimos a possibilidade de produzir belas fotografias"13. Coube a Jack Woody, o editor de The killing fields [Os campos de extermínio], fazer com que o argumento estético se encaixasse ao argumento da especificidade-do-meio-como-forma-de-arte e, junto a isso, projetá-lo para além da questão formal do belo ou da qualidade, além de infundi-lo de conteúdo humano:

Percebi que eram as fotos mais extraordinárias que eu jamais tinha visto durante anos. Por muito tempo, eu jamais havia experimentado a relação emocional que um espectador pode ter com temas. Pensei comigo mesmo: "é tão bom quanto uma fotografia pode ser". ${ }^{14}$

Uma linguagem tão crua está a anos-luz do vocabulário impassível dos curadores de fotografia do MoMA, mas pode decifrar por que, aos olhos deles também, "essas imagens poderosas merecem ser vistas por um público maior" e são "potencialmente relevantes para o estudo da fotografia em geral”. O que de fato é relevante é que Woody tenha falado da "relação emocional que o espectador tem com temas com pessoas - nas fotos" ${ }^{15}$, mais do que com as fotos em si, enquanto objetos de estudo. De repente, o caráter comovente que Roland Barthes julgava essencial ao "meio" fotografia pontua o discurso formalista do MoMA. O punctum de Barthes e a maneira como arrebata o espectador anulam a restrição ao studium, autoimposta pelo MoMA - de tal modo que se alguma referência específica à "fotografia em si" é convocada pelas fotos de Tuol Sleng, certamente tratar-se-á da foto tirada por Alexander Gardner de Lewis Payne/ Powell no corredor da morte, cujo punctum foi assim caracterizado por Barthes: "Ele vai morrer"16.

Sobriedade no desenho expositivo, textos de parede descompromissados e um astucioso esquivar-se da palavra "arte" nos pressreleases não conseguirão esconder o fato de que nosso interesse estético pela fotografia é despertado por sentimentos, emoções e projeções de empatia ou antipatia que se dirigem às pessoas nas fotos, para além das fotos em $\mathrm{si}^{17}$. Estou convencido de que alguma coisa dessa resposta 
17. Ver meu texto People in the image /

People before the image: address and the issue of community in Sylvie Blocher's L'annonce amoureuse. October, n. 85, verão 1998. p. 107-126.

18. Estou ainda às voltas com a questão, e tal é a razão de eu ter publicado muito pouco sobre o assunto. Ver meu texto Museumethiek na Broodthaers: een naïve theorie [A ética do museu depois de Broodthaers: uma teoria naïve]. De Witte Raaf, n. 91, maio / jun. 2001, uma versão em holandês e a única publicada de uma palestra que dei no simpósio "Ideals and ideology" [Ideais e ideologia], ocorrido no Boston Museum of Fine Arts, abril 1998. emocional ao pesadelo propriamente humano dos sujeitos fotografados nas fotos de Tuol Sleng influenciou a decisão do MoMA em adquiri-las. Supor diferentemente seria atribuir ao comitê de aquisição um injusto cinismo. A frieza, a reserva - e no caso de "Fotografias de S-21", sou tentado a acrescentar, a afetação de pudor - que são características do discurso do departamento de fotografia do MoMA não deveriam ser interpretadas ao pé da letra. Denunciam antes constrangimento do que afinidade por um formalismo pedante, ou aversão por um conteúdo humano e humanitário da fotografia. São manobras defensivas, assim me parece, destinadas a abafar a justificação humanista do espaço da fotografia dentro de um museu de arte. Imagino que estar no interior do cavalo de Troia quando se é defensor de Troia não seja a situação mais confortável de se estar, mas isso deixa a percepção mais aguçada. E imagino que os curadores de fotografia do MoMA estejam mais atentos do que os dos outros departamentos sobre os riscos de remexer "as ruínas do museu”, e que são, dessa forma, os mais preparados para abster-se da legitimação humanista do museu de arte em geral. Com "Fotografias de S-21", a manobra defensiva beira a fobia, algo compreensível. Em face do menor sinal de uma relação emotiva com as fotos e de compaixão por seu assunto, corre-se o risco de aproximação excessiva da leitura humanista - e assim, o risco de se proclamar Nhem Ein um artista, ou seja, um representante legítimo da humanidade no domínio estético.

Tudo isso pode ser pura especulação. Como eu disse, não vi a exposição no MoMA e, por razões que ficarão claras, sou incapaz de formar uma opinião justa sobre a decisão de adquirir e expor as fotos de Tuol Sleng. A ideia de que, com essa aquisição, a legitimação humanista da arte e da instituição de arte passava por sua prova mais difícil era, de qualquer modo, irrepreensível para alguém como eu que ficou sabendo da compra feita pelo MoMA no momento em que chegava em Arles. Mas o que me intrigou primeiro, antes mesmo de ver a exposição em Arles, foi o tipo de teste que ela representaria para uma legitimação alternativa da instituição de arte, na qual eu já vinha pensando ${ }^{18}$. A visão patrimonial, humanista argumenta que, uma vez que a humanidade possui esse bem coletivo chamado arte, todos têm o direito de ter acesso a ele. Proponho argumentar no sentido inverso: desde que todos tenham acesso a esse bem e sejam livres para, a qualquer momento, levar a julgamento o status de arte dele, sua preservação em instituições públicas de arte é então justificada. A apresentação ou a condição pública legitimam uma coleção ou patrimônio, não o contrário. A principal consequência dessa inversão no argumento huma- 
nista é transferir dos profissionais do museu para o espectador a liberdade e a responsabilidade de designar o "status de arte". Em condições cotidianas normais - ou seja, quando o museu coleciona e preserva certas coisas como arte e as exibe em nome da arte - essa transferência se realiza como um convite aos espectadores, que os incumbe de apreciarem os trabalhos esteticamente, sem maiores desdobramentos se eles consignam seus vereditos a si mesmos. Mas nas duas condições anômalas mencionadas antes por mim - quando coisas colecionadas como arte não são exibidas em nome da arte (situação, a propósito, que virtualmente se tornou regra no mundo da arte contemporânea), ou quando coisas que não são arte são, todavia, mostradas em nome da arte (como é o caso da fotografia vernacular no MoMA) -, então uma pressão real, não apenas simbólica ou convencional, é exercida sobre os espectadores, individualmente, para que batizem, eles próprios, as coisas em questão como "arte" ou "não arte”. Julgamentos estéticos adquirem, assim, a gravidade do 'ou isso/ ou aquilo' que não têm no cotidiano do museu de arte - e por certo não é esperado que tenham no contexto de um festival de fotografia durante o verão numa adorável cidade provençal banhada pelo sol. Teria sido lícito supor que a variedade de mostras que o festival de fotografia de Arles tinha a oferecer em 1997, como também as diferenças de status entre elas, ao revelarem toda a gama de usos artísticos e não artísticos da fotografia, aliviaria ou mesmo diluiria a gravidade que a exposição "S-21" solicitava - por razões políticas, não estéticas. O oposto era verdadeiro: sem "S-21", a ambiguidade deliberada do festival poderia ter gerado calorosas discussões em cafés sobre o status de arte desse ou daquele grupo de fotografias - mas discussões que não fariam ninguém perder o sono. A presença de "S-21" carregou essas discussões com uma gravidade exacerbada que provou ser muito mais de natureza estética do que política. Mesmo em meio a uma variedade de exposições contendo imagens de violência, "S-21" parecia fora de contexto, com uma solene e deliberada faute de goût que tornou a simples caracterização estética das fotos perturbadora de se escutar e embaraçosa de se pronunciar. Riley e Niven preferiram não falar em Arles; pode-se apostar que seria insuportável para um bom número de visitantes da "S-21" ouvi-los falar de "belas fotografias" e "impressões de qualidade excepcional".

A importância de se distinguir entre a alternativa proposta e a legitimação humanista da instituição de arte fica ainda mais evidente quando se considera que a inserção a que Cajoulle procedeu, da exposição "S-21" sob a rubrica $\mathrm{O}$ dever da memória, não estava isenta do cálculo humanista. Invocar os direitos humanos e suas violações é 
fundamental à prescrição do dever da memória. Ao se basear na ideia de direito humano, Caujolle pode ter negligenciado a singularidade das fotos de Tuol Sleng. Não acredito que inspirar compaixão pelas vítimas e por seus direitos fosse a mais importante de suas motivações, mas ele deve ter visto tal empatia como condição essencial à consciência política e à luta contra o esquecimento. Dado que a empatia pelos indivíduos nas imagens fotográficas é inseparável de nosso interesse estético pela fotografia, mais do que por outros tipos de imagens não indiciais (o punctum de Barthes, novamente), Caujolle estava fadado a apelar a uma espécie de humanitarismo sentimental para justificar sua decisão de incluir "S-21" no festival de Arles. Vejo-me forçado a analisar sem muita piedade sua atitude ética ao tomar tal decisão. Do ponto de vista político, não havia ambiguidade. Caujolle se recusou inflexivelmente a conferir a Nhem Ein e seus assistentes o título de artistas, ou, às fotos, o status de arte. Nhem Ein era um agente do regime de Pol Pot e, de modo algum, um representante da humanidade. As fotos eram o produto da polícia de um governo totalitário e de uma tresloucada burocracia genocida. Caujolle não as exibiu em nome da arte, mas diferentemente, em nome de um imperativo político chamado o dever da memória. No que lhe dizia respeito, a arte jamais estivera em questão. Suas declarações asseguraram que as fotos seriam exibidas acompanhadas de um rótulo virtual mas bastante visível dizendo "Isso não é arte", e com sua assinatura embaixo.

Não vejo razão para se duvidar da sinceridade de Caujolle; tentarei, então, ser tão claro quanto ele. Respeito e compartilho sua atitude ética com relação aos fotógrafos. Não estou menos inclinado a chamar Nhem Ein de artista do que ele está. Mas minhas razões são muito diferentes das dele: as minhas se sustentam no limite em que a estética conduz à ética e somente então à política, enquanto as dele, como as entendo, são integralmente políticas, e só são éticas na medida em que justiça em política pressupõe um sentido ético. Quaisquer que tenham sido as razões estéticas dele para alegar que a arte não estava em questão nas fotos de Nhem Ein, ou elas eram subservientes à causa política que ele abraçou, ou eram desautorizadas, denegadas e reprimidas. Novamente, não vejo motivo para questionar seu compromisso ético e político, que endosso e respeito. O que me preocupa é o descarte do estético, que não posso deixar de pensar como uma via que fatalmente abre caminho para algo como um retorno do reprimido. Não posso conceber clarividência política em assuntos de arte deixando de confiar na experiência estética, mas aparentemente esta não é a filosofia de Caujolle. O resultado é que ele fracassa em registrar a nova 
19. MASCOLO, Dionys. Autour d'un effort de mémoire: sur une lettre de Robert Antelme. Paris: Maurice Nadeau, 1987, p. 63. Dionys Mascolo (19161997) foi escritor e intelectual engajado, e segundo marido de Marguerite Duras. Ele e Georges Beauchamp resgataram Robert Antelme, o primeiro marido da escritora, de Dachau, em 1945. Dois anos depois, Antelme publicou L'espèce humaine [A espécie humana], seu relato da vida em um campo de concentração, que é igualmente uma meditação filosófica sobre a absoluta unidade da espécie humana. 0 que Antelme descobriu com sua experiência no campo de concentração é que, quando o conceito político, "positivo" e emancipador da espécie humana é destruído, a sobrevivência física e a dignidade moral têm de ser recobradas na “necessidade quase biológica de se pertencer à espécie humana". L'espèce humaine. Paris:

Gallimard, 1957, p. 11 (texto traduzido do francês pelo autor). Com essa referência cruzada a Mascolo e Antelme - poderia ter também mencionado If this is a man (1947) de Primo Levi - eu quis deixar claro que minha posição não é antihumanista, mas reconhece que o humanismo morreu em Dachau, Auschwitz e Treblinka. Não me importo com o nome que será dado à ética antropológica que categoria estética - sim, estética - que o Khmer Vermelho nos forçou a criar, a de imagens de genocídio. Não existe, pelo menos até onde eu sei, nenhum outro exemplo histórico de regime político envolvido com genocídio que tenha mantido sistematicamente um arquivo fotográfico das pessoas que exterminava. Mesmo os nazistas não o fizeram sistematicamente, e quando o fizeram, com frequência tentaram destruir as provas.

O ataque contra a espécie é um trabalho da espécie. A SS nazista não é diferente de nós. A inocência pessoal, por mais profunda que seja, não vale nada em face dessa solidariedade forçada com a espécie enquanto mensageira do mal, da morte, do fogo. Nenhum vestígio de humanismo nisso. ${ }^{19}$

Estas linhas foram tiradas de um texto que pertinentemente (ou talvez de modo nada pertinente) ecoa o dever da memória de Caujolle, uma vez que é intitulado "Autour d'un effort de mémoire: sur une lettre de Robert Antelme" [Acerca de um esforço de memória: sobre uma carta de Robert Antelme]. A dialética circular em ação na legitimação humanista da arte e da instituição de arte pressupõe que o respeito pelo humano define o humano. As linhas de Mascolo e, como pano de fundo para elas, o livro A espécie humana, de Antelme, rompem esse pressuposto. Talvez a maior incoerência filosófica do humanismo seja presumir que o comportamento inumano exclui alguns humanos da humanidade. A lição a ser aprendida com o Shoah, Mascolo nos lembra, é que ninguém pode ser excluído da humanidade: os torturadores são tão humanos quanto suas vítimas. Tornar Nhem Ein um representante legítimo da humanidade no domínio estético é obsceno mas coerente tanto com a qualidade de suas fotos quanto com a legitimação humanista da arte - que, conforme fica demonstrado, está arruinada. Embora concorde com Caujolle quando se nega a chamar Nhem Ein de artista, não acredito que suas razões sejam suficientemente livres do humanismo pré-Shoah. Por tudo o que ele disse para explicar e justificar sua atitude (ainda que, de modo revelador, não suas ações, como veremos), Caujolle parece ter recuado diante do que Mascolo chamou de "solidariedade forçada com a espécie como mensageira do mal, da morte, do fogo”. Ele não foi longe o suficiente na direção da cumplicidade com os assassinos; estancou súbito, antes de assumir por inteiro a obscenidade de seu próprio empreendimento.

Lembremos que, ao tomar conhecimento da exposição de Arles, Nhem Ein declarou-se orgulhoso de ser a "estrela" de um festival de fotografia na França e praticamente agradeceu aos organizadores o título de artista que, ao que parece, lhe haviam conferido. Isso já é 
nossa época requer (de preferência, nem "neo-humanismo" nem "pós-humanismo"ambos são pouco convincentes e ridículos), mas uma coisa é certa: uma vez que não liquidamos a condição humana lpace [que me perdoem] o cyborg e outras fantasias), devemos repensar essa condição, confrontar a terra assolada que herdamos do funesto século XX.

20. Essa questão foi levantada por mais de um comentador das fotografias do S-21 expostas no MoMA. Em seu subtítulo, o artigo de Michael Kimmelman

(New York Times, 20 jun. 1997) falou de "arte não intencional”, e Jerry Adler e Ron Moreau (Newsweek, 30 jun. 1997), de "arte acidental". A ideia de que os fotógrafos tinham involuntariamente produzido arte porque eram bem-treinados, bons fotógrafos, não estava, entretanto, implícita nos dois exemplos, mas sim a de que o MoMA tinha elevado indevidamente as fotos deles ao status de arte. Kimmelman, não obstante, faz a pergunta retroativa: "Isso significa que os assassinos que as tiraram são artistas? Genocídio pode ser arte?".

21. Ver WIMSATT, William K.; BEARDSLEY, Monroe. The intentional fallacy.

Sewanee Review, n. 54, jul. / set. 1946. p. 468-488. obsceno o bastante. Em todo caso, por ora lhe concedamos seu título, ou, ao menos, examinemos as bases sobre as quais esse título poderia ser concedido a ele. Por certo, nunca passou pela cabeça de Nhem Ein, na época, que seu trabalho era arte ou poderia ser visto como tal - mas quem vai saber? Diferentemente de Marc Garanger, que havia sido forçado pelo exército francês a fotografar mulheres argelinas "suspeitas" durante o serviço militar na guerra contra a Argélia, em razão de sua carreira civil de fotógrafo, Nhem Ein nem mesmo era fotógrafo profissional antes do Khmer Vermelho enviá-lo a Xangai com o propósito explícito de que fosse treinado nas técnicas de que precisaria para desempenhar sua tarefa ao lado dos genocidas. Não podemos descartar a hipótese de que ele desenvolveu um gosto genuíno pela fotografia durante seus estudos e de que se refugiou numa atitude estética a fim de ocultar a si mesmo sua cumplicidade nas atrocidades cometidas no S-21. Apesar de agora negá-lo, ele pode ter tido ambições artísticas conscientes, ao mesmo tempo motivadas e pervertidas por sua própria estratégia de sobrevivência. Há registro de que montou um estúdio fotográfico mais apropriado a uma prática refinada do que a meras fotos de identidade - uma excentricidade, dadas as circunstâncias. De fato, a qualidade de algumas das fotos de Tuol Sleng indica ser improvável que Nhem Ein e os fotógrafos de seu time não tivessem consciência do próprio conhecimento estético. Não sendo artistas "inconscientes", seria então possível dizer que eram artistas "desavisados", não "intencionais" ${ }^{\prime 20}$ ? O argumento pode ser moralmente repulsivo, mas é esteticamente relevante: Atget não queria que o vissem como artista, mas a qualidade indiscutível de seu trabalho fez com que ignorássemos seus protestos, e com razão. Para acalmar nossos escrúpulos frente ao risco de tratar Nhem Ein como Atget, poderíamos retrucar que, ao estar moralmente envolvido em um projeto vil, Nhem Ein perdeu qualquer direito ao título de artista. Mas este seria o argumento mais fraco de todos: Leni Riefenstahl foi uma artista, e estava muito mais envolvida com o regime nazista do que Nhem com o Khmer Vermelho, uma vez que ela não corria perigo. Nenhum empenho de escrutínio na psique, na consciência e nos brios de Nhem Ein nos convencerá do que há muito foi reconhecido em teoria estética como "falácia intencional"1. Para tentar entender o status a ser dado a essas fotografias, deveríamos nos voltar, em vez disso, para o consciente e a consciência moral de Caujolle. Esta última está acima de qualquer suspeita. O primeiro o deixa em apuros. Mesmo que tenha subestimado as ambiguidades inerentes ao contexto de recepção da "S-21", Caujolle devia saber que o rótulo "Isso é arte" seria anexado às fotos. Presumir diferentemente 
22. Apresentação pública de Christian Caujolle em Arles, 7 jul. 1997. Apud op. cit., p. 105-106. seria um insulto à inteligência estratégica dele sobre a situação. Colocar "S-21" no contexto de outras exposições fotográficas cujo status de arte cobria todo um espectro, desde foto-jornalismo de agência de notícias à mais "tradicional" e então à "pura" fotografia e destas à "arteproduzida-no-meio-fotografia" [art-done-in-the-photo-medium], foi uma atitude calculada, e o impacto da exposição deveu-se muito à sua posição de ambiguidade nesse espectro. Se a exposição acontecesse na embaixada do Camboja, ou em algum outro contexto humanitário, como um ritual político de catarse e reparação, o impacto seria completamente diferente. Alem disso, Caujolle deve ter intimamente anexado o rótulo "Isso é arte" às fotos, tenha ou não se dado conta ou reconhecido isso. Presumir diferentemente seria, desta vez, um insulto à sua familiaridade estética com a história da fotografia e a seu conhecimento sofisticado do potencial dela. Antes de decidir mostrar as fotos em Arles, ele as vira em Phnom Penh; captara seu impacto emocional; reconhecera tê-las apreciado tanto no nível estético quanto no ético e no político. Ele simplesmente não se permitiria deixar a palavra "arte" descrever sua experiência estética. Sua negação da qualidade propriamente artística das fotos é uma denegação em um sentido quase freudiano e não difere da rejeição de muitas obras de arte de vanguarda por críticos que captaram o impacto estético dos trabalhos mas não conseguiram lidar com a carga emocional que eles desencadeavam.

O que me leva a falar em denegação não é que Caujolle tivesse agido de má-fé ou inconscientemente. É que julgamentos estéticos são involuntários e a frase "Isso é arte" expressa um julgamento estético. A palavra "arte" nos vem à cabeça, possivelmente contra a nossa vontade, sempre que um artefato humano desencadeia uma reação estética que justifica uma comparação com a arte já existente. No contexto de um museu de arte, o apelo a essa comparação é explícito e desejado - é o que significa "expor arte em nome da arte". No Museu do Genocídio, em Phnom Penh, as fotos não são mostradas como arte, e nem em nome da arte. Todavia, será que lá a experiência de Caujolle com as fotos não se situava em um universo comparativo de julgamentos estéticos sobre arte? Há comprovação de uma resposta positiva no fato de ele próprio reconhecer que "esses retratos inegavelmente apresentam um interesse estético", e que "certos retratos poderiam sem sombra de dúvida encontrar lugar em uma exposição de Irving Penn ou Richard Avedon"22. Anexar o veredito "Isso é arte" às fotos é inevitável a partir do momento em que se alude a Irving Penn ou Richard Avedon, queirase ou não admitir. Caujolle não negou a natureza estética de sua reação inicial às fotos. $\mathrm{O}$ que ele negou foi a legitimidade de transcrever sua 
experiência estética na sentença "Isso é arte". Ele deve ter se dado conta de que, se admitisse que as fotos de Nhem Ein eram arte, teria também que admitir que Nhem Ein era um artista. Mas não acredito ser esta a última palavra em tal raciocínio; pode-se fazer uma outra inferência a partir das mesmas premissas. Antes de introduzir o assunto, precisamos questionar um outro aspecto da justificativa de Caujolle sobre sua atitude e desvendar outra denegação.

Ele diz respeito ao modo como Caujolle instalou as fotos. Com o intuito de demonstrar que sua atitude havia sido ética e política em vez de estética, Caujolle explicou que fizera de tudo para desestetizar, o quanto fosse possível, a instalação. Sua estratégia favorita para alcançar esse propósito era não tomar decisões - ou pelos menos é o que diz a história. Afirmou ter aceitado o primeiro espaço que a cidade de Arles oferecia para a exposição: uma sala um tanto inóspita, equipada de modo amador, que já havia servido de espaço expositivo e agora se encontrava em condições de abandono. Havia organizado as fotos em uma grade que ocupava inteiramente uma única, e apenas uma, parede da sala. Determinara o tamanho das ampliações das imagens tendo por base o número total de fotos que caberia de maneira precisa nessa disposição. Tinha evitado qualquer composição e sublinhara a arbitrariedade da montagem colocando a foto de um menino que ostentava um "número 1" no canto esquerdo superior da grade. A parede era precariamente iluminada por uma série de holofotes, que sugeriam não terem sido arranjados intencionalmente, mas mantidos da maneira como estavam. De fato, havia deixado os holofotes do mesmo jeito em que os havia encontrado. Finalmente, imprimira um texto explicando as razões da exposição em uma superfície transparente de plástico, que não fixara na parede, acima ou abaixo das fotos, nem em uma parede adjacente, mas que deixara jazendo no chão, diante das fotos, como se a montagem ainda estivesse em processo. O texto tinha a largura da grade e se estendia por muitas linhas, de tal modo que era preciso recuar e avançar para lê-lo, e, ao mesmo tempo, sujeitar-se a uma fileira de olhares fixando a partir das fotografias, com a diversidade estilhaçada de suas aparências e a singularidade de suas atitudes. Todas essas decisões, ou não decisões, eram éticas e deliberadamente antiestéticas. Ouvi essa explicação de uma fonte confiável, antes de minha visita, e já suspeitava que separação assim tão conveniente entre o ético e o estético não se sustentaria. A experiência efetiva da montagem confirmou minhas suspeitas. Estava claro para mim, não obstante ele negasse veementemente, que Caujolle havia tomado um número de decisões estéticas precisas, e que estas eram muito menos convencionais e assim 
muito mais artísticas do que as que são habitualmente tomadas por curadores ao montarem uma exposição. Ele se comportou como um artista que produz uma instalação, um bom artista, politicamente consciente e responsável, que sabe como a legitimidade ética da arte depende de decisões estéticas, ainda mais quando elas tomam a forma de gestos calculadamente antiestéticos.

Naquele momento comecei a entender por que Caujolle havia tão obstinadamente negado que as fotos de Nhem Ein fossem arte: não tanto porque teria que admitir que Nhem Ein era um artista, mas porque estava relutante em admitir que era, ele próprio, o artista. Contudo, que melhor confirmação poderíamos imaginar daquilo que Mascolo chama de "solidariedade forçada com a espécie como mensageira do mal, da morte, do fogo"? Que melhor reconhecimento do fato de que ninguém pode ser excluído da humanidade em cujo nome os artistas dizem falar? Acredito que Caujolle recuou, mas ele talvez tenha uma outra explicação; provavelmente compartilhe o ponto de vista corrente, de que, com a exceção desses grandiloquentes egomaníacos que produzem o pior tipo de arte reacionária, artistas não pretendem falar em nome da humanidade. Ele seria assim vítima do mesmo mal-entendido que alimenta todas as teorias antiestéticas da arte que acabaram por dominar o debate nos últimos 40 anos. A teoria alternativa de que, conforme creio, nosso tempo precisa defende que artistas legitimamente reivindiquem falar em nome da humanidade, contanto que seja concedido à humanidade incluir os incultos e de mau gosto, os inimigos da arte, os bárbaros, os criminosos, e mesmo - usando aqui as três categorias surgidas com o julgamento de Nuremberg para classificar os perpetradores de crimes imprescritíveis - aqueles culpados de crimes de guerra, genocídio e crimes contra a humanidade. "Nenhum vestígio de humanismo nisso", para citar Mascolo novamente. A estratégia antiestética de Caujolle como artista que produz instalações confirma de modo definitivo que tal humanismo encontra-se deslegitimado como fundamento da arte. Mas as denegações de Caujolle, ressaltadas pelo fato de que seus atos contradizem suas palavras, mostram que a deslegitimação não é o bastante. Não queremos ficar encurralados em aporias tais como a de Adorno quando afirma, em "Crítica cultural e sociedade" (1951), que escrever poesia depois de Auschwitz era barbárie (o que ele então retificou em Dialética negativa, 1966). É uma relegitimação que devemos buscar, mesmo que isso signifique defender Caujolle em face de suas próprias denegações.

A legitimação humanista afirma que a arte é um bem coletivo da humanidade. E se a humanidade incluir criminosos de guerra e pessoas 


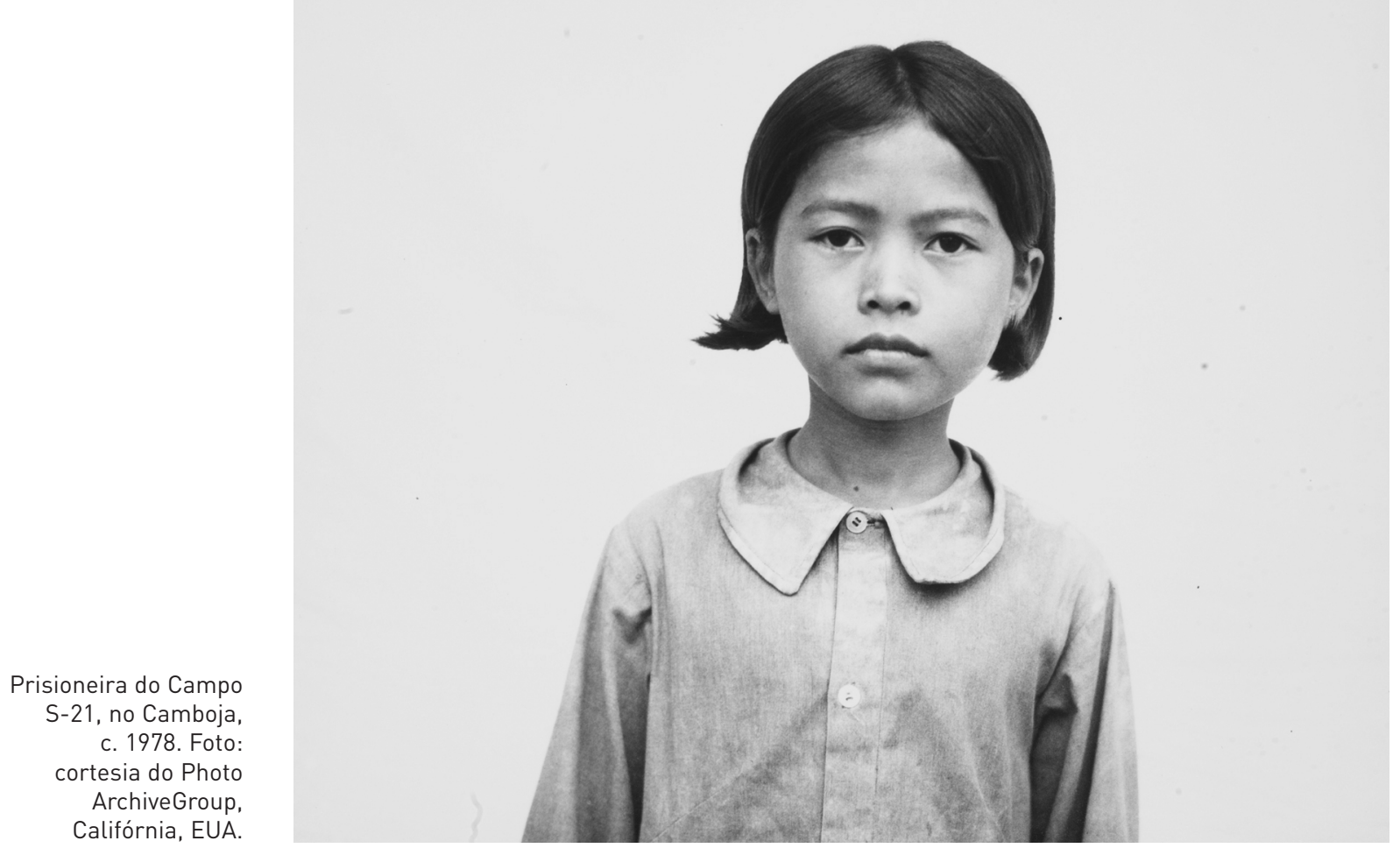

culpadas de genocídio? Dessa mesma legitimação decorre que artistas são representantes da humanidade no domínio estético. E se eles na verdade forem representantes, na dimensão estética, de perpetradores de crimes contra a humanidade? Possivelmente, em nenhum dos dois casos Nhem Ein poderia ter direito legítimo ao título de artista. A conclusão, todavia, não é que o título de artista foi irremediavelmente maculado ou que praticar fotografia após Tuol Sleng se tornou algo tão bárbaro quanto escrever poesia depois de Auschwitz, conforme uma vez pareceu a Adorno. A conclusão se detém na transferência imposta ao título de artista: agora é como se Caujolle tivesse se encarregado de substituir o artista ausente, e sem maiores reivindicações a uma legitimidade. Reconhecer essa falta de legitimidade é o primeiro passo em direção à relegitimação, e Caujolle deu esse primeiro passo, muito paradoxalmente protegido por suas denegações e pelo modo como estas entravam em contradição com seus atos. Ele assumiu o lugar de Nhem Ein, simbolicamente se pôs no lugar dele, vestiu sua pele, assumiu o papel do artista monstruosamente ilegítimo, e se responsabilizou pelas qualidades estéticas de suas fotografias. Fez isso na qualidade de curador das fotos, protegido pelo fato de que não era seu autor. E, fazendo assim, ele transferiu o fardo para o espectador: não obstante todas as suas denegações, ele decidiu que as fotos mereciam ser vistas, tanto por suas qualidades estéticas como por sua relevância política. Dirigiu-as a nós. Dirigiu-as a mim. 
Em toda a minha vida, nunca senti que um julgamento estético podia pesar tanto nos ombros de alguém. Nem, tampouco, senti tão intensamente que tinha a responsabilidade moral de fazer um julgamento estético. A experiência foi dolorosa, e naquele momento eu não podia explicar por quê. Acredito que agora posso. É algo que diz respeito ao fato de os julgamentos estéticos serem comparativos e involuntários. A verdade é que foi inacreditavelmente fácil - não apenas fácil, mas automático - ver nessas fotos reminiscências de Richard Avedon (não tenho certeza sobre Irving Penn, mas também não sou letrado o suficiente em fotografia). Não podia evitar que a foto de Avedon de uma vítima de napalm, por exemplo, virasse um anteparo através do qual eu via as fotos de "S-21". As melhores dentre elas, de toda maneira, estavam carregadas de uma espécie de pungência humana que se espera de uma boa fotografia de Avedon, e isso as tornava insuportáveis. A experiência que tive delas era como a experiência que se tem de um trabalho de vanguarda extremamente provocativo do tipo de trabalho que provoca uma reação inicial de aversão, e que lentamente se aprende a apreciar -, mas na ordem inversa. Aqui a reação inicial foi de empatia barata e boa consciência, ao passo que o conhecimento do contexto em que as fotos haviam sido tiradas apenas contribuía para que se agravasse o potencial delas para o sentimentalismo - tornando-se revoltante, mesmo. Tive de lutar contra minha reação inicial; era isso que as fotos pediam. A responsabilidade moral de que me senti investido vis-à-vis essas imagens suscitou uma recusa e uma rejeição dos sentimentos estéticos que elas produziam. Claro que isso não poderia se dar, pois sentimentos estéticos são involuntários: não poderia negar tê-los tido sem ser desonesto. Ao invés disso, as fotografias, na verdade, solicitavam uma experiência estética prolongada e renovada. Fiquei uma hora com elas em minha primeira visita e voltei para mais uma hora no dia seguinte. Eu me flagrei com os olhos grudados nas fotos - ou melhor, nas pessoas das fotos, em cada uma, e por um bom tempo, até que elas emergissem do anonimato do extermínio em massa e se transformassem em indivíduos de novo. Não que não fossem indivíduos em minha primeira experiência; é que sua individualidade, envolta em um humanismo genérico e banalizada pela "estética Avedon" que as fotos muito facilmente evocavam, tinha de ser resgatada de outro lugar - na maioria das vezes, de algum pequeno detalhe que dizia alguma coisa específica, não sobre suas vidas ou personalidades, mas sobre sua agonia atual, as condições materiais da detenção, o medo em seus rostos, ou o desamparo desconcertante em seus olhos no exato momento em que a foto era tirada. Eu tive de me 
23. Ver meu ensaio Do artists speak on behalf of all of us? In: COSTELLO, Diarmuid; WILLSDON, Dominic (Ed.). The life and death of images, ethics and aesthetics.

Londres: Tate

Publishing, 2008. p. 140-156. dedicar a cada foto, a cada pessoa nas fotos, individualmente, antes que pudesse perceber o olhar delas - que na maioria das vezes estava de fato dirigido com intensidade à câmera - como se fosse dirigido a mim, em pessoa. Somente então as pessoas nas fotos ressurgiram da morte, e somente então essa exposição insuportavelmente controversa ganhava sua legitimidade verdadeira.

Essa não é absolutamente a última palavra sobre a nova legitimação da arte e da instituição de arte de que a deslegitimação do velho raciocínio humanista precisa. "S-21" continua sendo um caso extremo, e felizmente raro. Por que será, então, uma prova tão crucial? Por que a cumplicidade de Nhem Ein no genocídio cambojano nos fornece um exemplo único de não arte, que tem o mesmo valor paradigmático para a teoria da arte de outros exemplos inofensivos porém bem mais notórios, como os readymades de Duchamp? Será por que as fotos de Nhem Ein exploram e transgridem os limites da arte? Será por que elas nos forçam a conceber a arte para além das fronteiras do que é humanamente aceitável? Não acredito em semelhantes raciocínios. Têm sido usados além da conta para justificar supostos trabalhos da não arte, e a meu ver nunca se aplicaram a uma arte realmente boa, nem explicaram por que a negatividade em arte se transmuta em qualidades positivas. $\mathrm{Na}$ crítica de arte dá-se muito crédito, e de modo um tanto complacente, à representação do trauma, à estética do abjeto, à celebração do repulsivo, à fascinação por filmes violentos, à estetização de catástrofes e terrorismo e a outros sintomas mórbidos. A declaração de Karlheinz Stockhausen de que 11 de setembro foi uma obra de arte deveria dar fim a esses sintomas, pois mostrou qual é a verdadeira natureza deles. Recapitulando: por que "S-21" é uma prova crucial para a teoria da arte? 1) Porque, como espero ter de algum modo demonstrado, a nova legitimação da arte e do museu de arte submete a reivindicação humanista da representatividade universal do artista ao teste de realidade da destinação universal do trabalho de arte; 2) porque não tenho outro modo de saber se um trabalho de arte é portador de uma destinação universal exceto o sentimento de ser pessoalmente visado por ele; 3 ) porque, mais frequentemente do que nunca na arte verdadeiramente inovadora, esse sentimento depende por completo de minha capacidade ou vontade de me destinar ao trabalho de arte, fazendo com que ele, dessa maneira, se destine a mim; e 4) porque, no caso de imagens provenientes não apenas de intenções assassinas mas também genocidas, essa correspondência, que faz com que a pessoa vise ao trabalho e o trabalho à pessoa, torna-se imperativa, em razão da certeza absoluta de que o fotógrafo não visou a seus modelos ${ }^{23}$. Pertence à definição de 
Na página ao lado, prisioneiro do Campo

S-21, no Camboja, c. 1978. Foto: cortesia do Photo Archive Group, California, EUA. genocídio que as pessoas exterminadas são aniquiladas em sua humanidade antes mesmo de serem efetivamente assassinadas. Não foi Nhem Ein quem executou as vítimas; a seus olhos, elas já estavam mortas uma vez que foram reduzidas a coisas às quais não se fala e que logo serão descartadas. É por isso que a responsabilidade de se dirigir a elas é imperativamente transferida para o espectador das fotos, seja Caujolle, seja você ou eu. Chamar as fotos pelo nome de arte, batizando-as - "Você é arte" -, é apenas uma forma, a mais desajeitada, sem dúvida, de se ter certeza de que as pessoas nas fotos têm sua humanidade restaurada; e apenas isso - não seu tão discutido status de arte - é decerto o que importa. Falar sobre sustentar o papel de artista que Nhem Ein não pôde assumir é uma outra forma de dizer o mesmo. Nesses termos, não há nada de honorífico na palavra artista. Quando muito, testemunha-se a impossibilidade da reivindicação de se falar em nome de todos nós sem que se fale pela parte vil da espécie humana tanto quanto pela sua parte pacífica e civilizada.

junho de $1997 \backslash$ novembro de $2004 \backslash$ abril de 2007

Thierry De Duve, teórico da arte contemporânea, vive em Bruxelas e é professor na Universidade de Lille 3. É autor de vários livros, incluindo Kant after Duchamp (Cambridge: MIT Press, 1996). Foi curador de "Voici - 100 ans d'art contemporain" no Palais des Beaux-Arts, Bruxelas, 2000, e do pavilhão da Bélgica na Bienal de Veneza de 2003, com Sylvie Eyberg e Valérie Mannaerts.

Tradução de Juliana Moreira. 


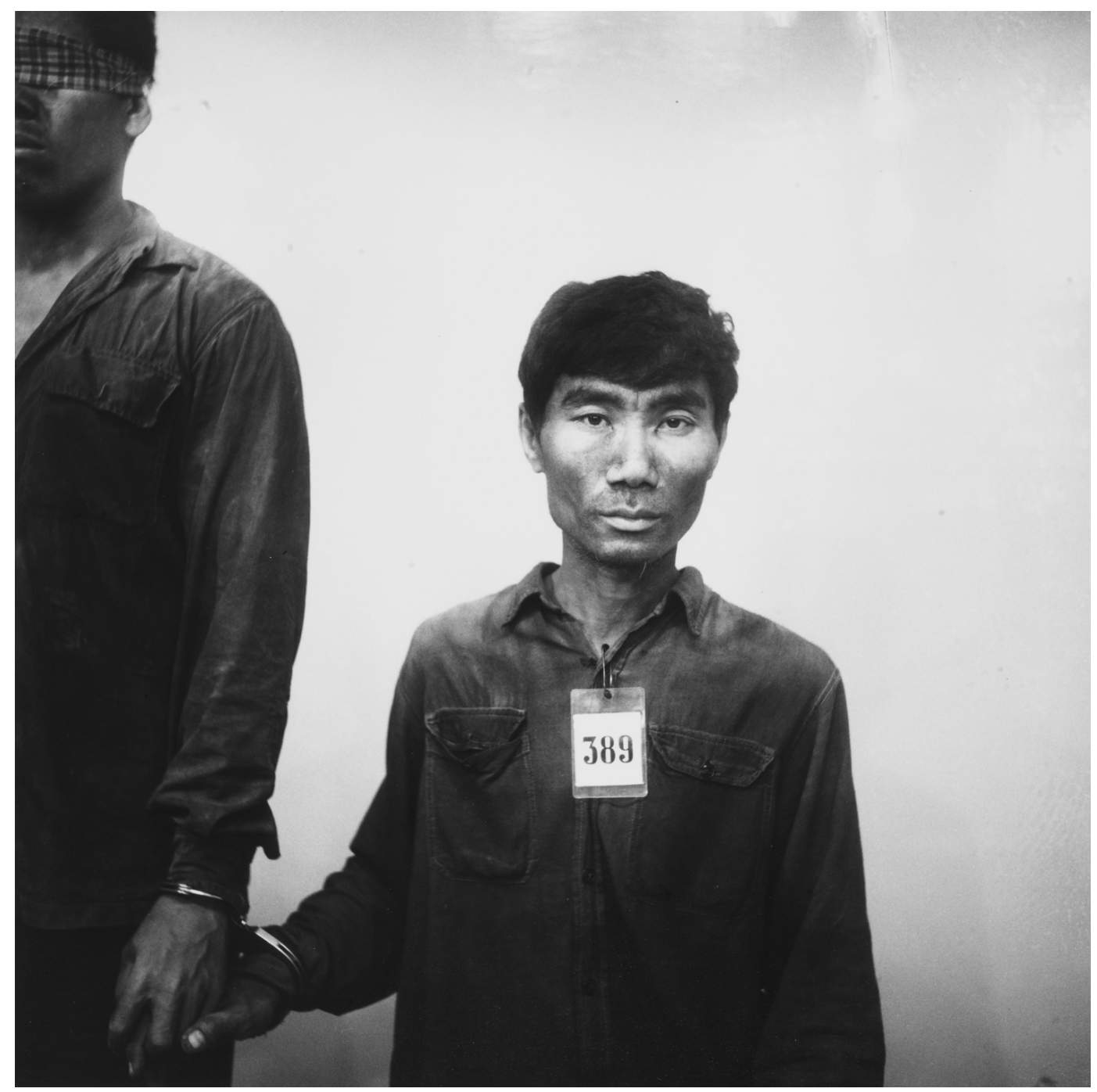

